\title{
Tradable traffic rights for urban transport
}

\author{
E. Musso, C. Burlando \& C. Sillig \\ CIELI, Italian Center of Research Excellence in Integrated Logistics, \\ Department of Economics and Quantitative Methods, \\ University of Genoa, Italy
}

\begin{abstract}
The paper aims at studying the theory of tradable pollution rights applied to urban mobility. In particular the paper focuses on the urban congestion problems and investigates the possibility to keep under control not only urban pollution but congestion through tradable rights applied to traffic management.

The introduction of tradable rights in urban mobility is considered in the aim to establish a market system where traffic is kept under control at a given level. Tradable rights are exchanged between different subjects on the basis of their different need to travel and of their consequent willingness to pay.

This gives place to a market for rights to circulate at a market price which results from the intersection of supply and demand of tradable certificates. Price is not, therefore, fixed by a policy maker.

The paper discusses different schemes of tradable permits markets and focuses on the main effects and problems arising from the application of this tool: fixing circulation level, defining criteria to distribute certificates, preserving market competition and urban development.

Furthermore, the paper investigates some possible solutions to emerging problems and analyses the possibility of combining tradable permits and other policies in order to point at an organic governance of urban mobility.

Keywords: urban mobility, tradable rights, traffic, market, governance of urban mobility.
\end{abstract}

\section{Introduction}

Inspired by Coase's theory on property rights [1], Dales [2] proposed in 1968 the use of tradable permits as a regulation tool for the administration of environmental resources. In the most common scheme, a maximum level of 
utilisation of a given resource is defined and - for free or against payment unitary property or usufruct rights on the resource (the permits) are divided between the subjects. The establishment of private rights on goods that were formerly exempt of them, leads to a market in which the permits (defined as the resource) will acquire a price and will be traded in accordance with the same principles that rule a normal private good market

For the application of tradable permits directed towards externality reduction, the Public Authority fixes beforehand a pollution level, i.e. a level of environmental damage that is considered "acceptable" (equality between the marginal cost of externalities and the marginal cost of their reduction). It then distributes between potential polluters, on the basis of predetermined criteria, a quantity of tradable permits proportionate to the acceptable pollution level previously fixed. After the initial distribution, the permits will get traded between the actors on the basis of their different necessity to pollute, defining in this way a "pollution market price" that is not fixed by the Public Authority but results from the matching of demand and supply of permits.

The demand of permits is therefore represented by the marginal cost curve of pollution reduction (Camagni [3]) while the supply is a vertical curve since the permits supply is exogenously fixed by the Authority. The subjects that can reduce pollution with a cost inferior to the permit price will sell their right to pollute to those subjects whose pollution reduction costs are higher than the price of permits. The exchange occurs because both parts get a benefit from it. It brings to a transfer of resources from users to the State only if the Public Authority has initially distributed the permits under payment. If the permits have been distributed for free, there is not such a transfer.

Figure 1 shows the effect of tradable permits on externalities. The pollution reduction marginal cost $\mathrm{MC}$ represents also the demand for permits (since the subject will prefer to pollute if the pollution reduction cost is higher than the permit cost). Therefore, the function highlights the quantity of permits demanded for every price level. For example, at price $O P_{l}$, the quantity of purchased permits will be $O Q_{1}$ since for every point to the right of $O Q_{I}$ the polluter gets a benefit from reducing his pollution instead of buying permits, while to the left of $O Q_{1}$ it will be advantageous for him to purchase permits instead of reducing pollution.

If the Authority wants to fix an acceptable level of pollution, e.g. $O Q$, it will issue a quantity of permits equal to this level. The supply of permits $S$ will be a vertical curve, passing by the fixed amount of permits $O Q$. Therefore, the price will be settled in $O P$ that corresponds to the intersection of the demand curve represented by $M C$ with the supply curve $S$.

Let us assume that only two polluters exist (figure 1-b). Their demand curves for permits are represented by $M C_{1}$ and $M C_{2}$, and their sum represents the market demand curve. If $S$ is the supply of permits, the price will be $O P$, and the two polluters will respectively demand the permits quantity $O Q_{1}$ and $O Q_{2}$. Assuming that initially the same quantity $S / 2$ has been distributed to the two subjects, the polluter whose cost for reducing pollution is higher will gain from a purchase of permits, while the other one will gain by selling them. 


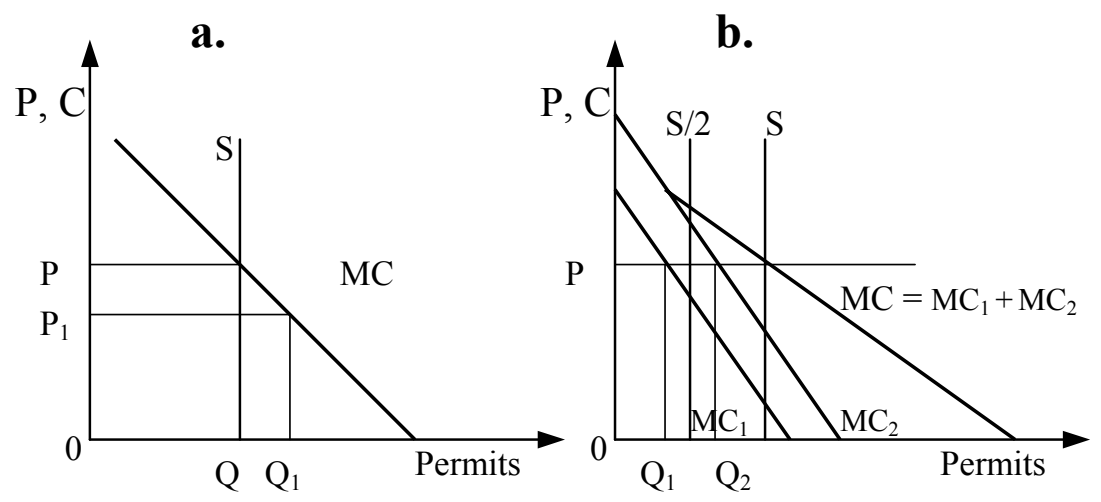

Figure 1: Externalities reduction trough the use of tradable permits (Danielis [4]).

\section{The concept of tradable permits declined to urban traffic governance}

So far, the major expression of tradable permits has been in the regulation of air pollution as in the case of either the Acid Rain Program (tradable permits on $\mathrm{SO}_{2}$ emissions) instituted in 1990 in the USA with the Title IV of the Clean Air Act Amendments or the recent activation of the 2003/87/EC directive on $\mathrm{CO}_{2}$ emission trading for some sectors of the European Union industry within the Kyoto protocol engagements on reduction of global warming emissions (Pozzo [5]).

In the transport sector, tradable permits scheme internal to the single car constructors firms have been implemented in the USA with the CAFE program and in California with the ZEV program - CNT [6]. Both these programs aim at simplifying the programmatic goal of eco-compatible vehicles production.

The use of tradable permits principle in the management of private urban traffic will consist in a first stage of definition of (i) the object of regulation (traffic level during peak hours, daily transits, etc.); (ii) the area subject to the policy; (iii) the quantity of permits emitted. Furthermore, it will be necessary to define whether the permits will be sold or distributed for free. If the second solution is selected, it will be necessary to decide the distribution criteria. The grandfathering principle, that for urban traffic can for instance consist in a distribution based on car ownership before the policy has been implemented, is often followed (cfr: $\S 3$ ). Once the market has been prompted, the price of permits will be established according to demand and supply, i.e. to the different characteristics of the demand for private mobility of the individuals: those who derive a high utility from the use of private vehicle will be ready to buy permits to other owners, while others, given the market price, will prefer to renounce to 
some displacements and/or to use public transport in order to profit from the selling of their permits (Goddard [7]).

Because of their peculiarity, tradable permits appear as an interesting solution to conciliate the advantages of two important tools for urban traffic governance: command and control norms and fiscal tools (especially road-pricing).

The impossibility (or the excessive cost) of knowing exactly the reaction of drivers to the raising of a tax (elasticity of demand to price) make sometimes (for instance with pollution peaks) preferable to fix an inflexible norm on maximum level of either pollution or traffic. The regulation policy such as traffic bans or traffic limitation scheme based on vehicle registration numbers are however particularly inefficient since they ignore the differences in the utility that the different drivers get from the use of private vehicle. With the adoption of a system such as tradable permits, the allowable ceiling would be reached with a minimum loss of efficiency (mostly due to transaction costs) since the individuals with higher willingness to pay for the private car use would buy the right owned by those who get a lower utility from them. Hence, in some cases, tradable permits appear more effective than fiscal tools and more efficient than normative ones. Moreover, with regard to fiscal policies and if the permits would be given for free, this policy would be superior in terms of acceptability and equity since the public authority would remain out of the monetary flow (on the contrary of taxation) and there would be the opportunity of a money transfer from high income people (who give a higher money value to time saving) to those with a low income.

Therefore, the objective is the investigation of tradable permits' potential as a tool for managing urban traffic, reducing air pollution and most of all traffic congestion. At first approach, there are two kind of applicable typologies of permits: based on pollutant emissions release and on vehicle use. Apart from presenting considerable technical restrictions to a correct implementation, a defect of the first kind of permits is due to the fact that the transition to a low emission car fleet could make the tradable permits policy not sufficiently effective when it comes to traffic reduction (Raux [8]). For this reason the attention is here oriented on vehicle use permits. The pollution reduction objective will be partly reached through the reduction of private car use, while in this case the transition to a less polluting car fleet has to be reached trough complementary policies. It is nevertheless necessary to notice that congestion reduction can be reached - apart from journey reduction and shifts in modal split in favour of collective transport - also trough an improvement of the temporal split (less transits during the peak hours), i.e. without affecting the total quantity of private traffic. A policy of this kind, advisable in terms of an efficient use of the infrastructure, tends to be ineffective in terms of emissions reduction.

\section{Critical issues and application problems}

The application of vehicle use permits to urban transport presents some difficulties that can be summarised as follows: 
- individuation of the regulation object and of the traffic level considered socially efficient;

- definition of the permits assignment criterion;

- $\quad$ definition of the area and/or subjects submitted to the policy;

- $\quad$ safeguard of the market competitiveness.

Although passengers and freight urban transport are closely related, they present different specificity that need a separate analysis of the two cases, namely when it comes to their enforcement.

\subsection{Critical application issues in freight transport}

The identification of the "optimal" circulation level is simpler than what would be the identification of the pollution optimal level since in a cap and trade system the cap can be defined according to the number of transits necessary to the city in conditions of freight transport distributive efficiency: ideally the transits number that would be necessary for the economic life of the city if the logistic organisation would wholly be in the hands of an unique operator (thus allowing for maximum load coefficient and minimum transits).

If daily permits were distributed, freight transport would hardly succeed in reducing concentration and congestion during (mainly morning) peak hours because of strong constraint on the goods reception side: impossibility of night deliveries because of noise; impossibility of deliveries beyond the first morning hours for fresh alimentary goods; difficulty of diluting delivering across the day because of unavailability of shopkeepers occupied in customer service.

Therefore - instead of a peak hours permits' system as it can be proposed for passengers transport (cfr: $\S 3.2$ ) - when it comes to freight transport, it would be better to define a scheme directed toward a better use of the vehicle carrying capacity and to the disincentive of one's own transport. Hence, if the permits were connected either to the kms driven or to the entrance in the policy area, it would be possible to encourage the rationalisation of the loads and of the deliveries routes thanks to the operators' incentive to limit $\mathrm{km}$ and entry (i.e. permits and their cost), deliveries being equal.

Another problem in using vehicle use permits in freight transport is the definition of the permits assignment criterion. The non applicability of the Coase theorem [1], especially because of high transaction costs and - with permits assigned under payment - income effect, brings, with regard to the final equilibrium, to a non indifference of the initial permits assignment criterion. Literature resolves the problem of the assignment of permits with different methods ramping from the historical approach to public auction and mixed systems.

With the "historical" allocation (grandfather rule) the rights are assigned on the basis of previous use, with the advantage of a better protection of established interests and consequent higher acceptability by the stakeholders. Nevertheless, the disadvantages of this assignment method are quite relevant. Particularly, except if the assignment is fixed to a lower level than the actual one or is gradually reduced over time, the grandfathering system can be scarcely able to contain the traffic level. 
In the freight sector, another possible disadvantage of the grandfather rule is represented by the possible market fossilisation that can reduce its contestability. If the whole amount of permits was distributed between the operators already present in the market, an entry barrier to new operators would be set up, that would bring to competitiveness reduction and market distortion. In order to avoid such an effect, a percentage of the permits should be kept by the Public Authority with the aim of allowing the entrance of new operators.

On the other side, given the initial expense, a public auction mechanism - that presents a lower risk of permits non-use/immobilisation because of the higher opportunity cost - will present the disadvantage of a lower acceptability degree.

The third problem is represented by the definition of the area and/or subjects submitted to the regulation policy. The dimension of the area and the number of subjects involved must in fact be such to allow a certain wideness i.e. market liquidity. Moreover, a small scale application could bring to a market distortion to the detriment of the operators who move in the permit area.

A fourth possible problem is related to the safeguard of market competitiveness. With tradable permits, there is still the risk that poor market liquidity make hamper the exchange mechanism on which the market is based. It is necessary to avoid that freight transport operators, once they have received the permits, could prefer to keep them instead of exchanging them because of fear of a future price increase (making therefore dangerous for the market structure a price expectation higher than their storing price) or for using them as a deterrent to the entry of new competitors. In such a case there can be babysitting practices (Barret [9], Bonnafous and Giret [10], Carlucci [11]) i.e. permits kept and unemployed (it is therefore possible to imagine the application of the "use it or lose it" rule used for airport slots trough which the authority could avoid a strategic fossilisation of the permits). The creation of a public authority for warranty of permits trading and possess regularity is hence desirable. The warranties necessity is present both with grandfathering and public auction distribution, even if the latter presents a higher opportunity cost of permits and hence a lower probability of keeping them unemployed. Moreover, in the case of public auction, the procedure could be divided in three auction classes (big, medium and small operators), so as to avoid that the subjects with higher financial availability buy up the whole or major part of the permits, transforming the tradable permits policy in a competitiveness limitation instrument. The Authority must therefore be competent with regard to the following issues:

- permits assignment regulation on the basis of the selected criterion;

- $\quad$ absence of banking and permits storing;

- market access maintenance: respect of competitiveness rules and control on possible collusive practices.

The last element of complexity in the application of tradable permits is referred to the control and sanctioning. It's obvious that a tradable permits system cannot work without a monitoring system on:

- market contestability (assignment trough the selected criterion, prohibition of practice that reduce the access to the market of urban logistics, etc.);

- $\quad$ effectiveness (traffic reduction, control on congestion, etc.). 
Finally, the policy cannot run without a suitable enforcing and sanctioning system that can act as a deterrent for illicit behaviours. Therefore, the sanction must be considerably higher than the permits price so as to encourage the market to work and hence the sale of permits, that must be advantageous compared to the risk of a high sanction.

\subsection{Critical application issues in passengers transport}

Like for freight transport, a first kind of problem for the application of vehicle use permits to passengers transport, is the fixing of the circulation level that is considered as socially efficient.

First of all, in a limited space such as a city, permits linked to km don't appear applicable to passengers' mobility - except if a satellite technology is used. In fact, such a scheme would not allow one to distinguish between the $\mathrm{km}$ that people drive in city and out of it, and therefore it is only applicable to a "closed" system (as can be some urban systems of freight distribution).

For urban passengers transport, it seems therefore more suitable to define daily vehicle use permits or permits regarding particular periods of the day. The identification of the socially efficient level of circulation could then be based on the infrastructure congestion threshold.

Nevertheless, if permits for the whole day were issued, people are likely to concentrate their journeys (i.e. their use of permits) during the peak hours. Even if the maximum number of daily permits emitted was defined on the basis of the road infrastructure maximum capacity (capacity beyond which congestion grows up), this will not resolve the problem of balancing between peak and off-peak hours: the maximum infrastructure saturation cannot be surpassed in some hours thanks to a compensation during the off-peak hours. A "compensation" or "balancing" effect that exists instead with pollution: even if pollution threshold is surpassed in some hours/days/periods, this can be compensated with hours/days/periods of low emission levels, precisely because of environment regeneration capacity.

This lack of "infrastructure regeneration" capacity and the fact that congestion problems are not uniformly distributed during the day brings to hypothesise the application of daily permits - with annual validity - to the sole peak-hours (i.e. allowing people to drive without permit during the off-peak hours), such to avoid infrastructure congestion during peak-hours trough a modal split in favour of public transport (to sell permits) and a traffic better diluted on the whole day (to save permits).

A second possible problem is related to the definition of the assignment criterion that can be done on the basis of the historical approach, with public auction or with mixed criteria. On this argument, the considerations already done for freight transport can be applied. Nevertheless, for passengers' mobility, the grandfather rule that attribute permits on the basis of car ownership make the system unfair because of the correlation between car ownership and income. A permits assignment on the basis of driving licence possession or resident population seems more equitable even if it will be necessary to consider the continuous variation during the year of the contingent of subjects potentially 
interested in the permits market (young who reach the age to get the driving licence, births, immigrants, etc.). For this reason it seems correct that the Public Authority keeps a share of permits available for the "new entrants".

The third issue concerns the definition of the area and/or subjects submitted to the regulation. Like in the other case, the area dimension and the involved subjects must brought to a market significance from the very beginning, and it can be suitable to hypothesise an application of the permits policy to the city users too. Yet a large range application is in contradiction with the administration tradition, driven by political motivation, of a highly gradual implementation of new policies. Therefore it is important to stress that tradable permits are a kind of tool that becomes effective only if the market and the submitted subjects are from adequate dimensions.

For passengers transport, the fourth problem of competitiveness guardianship does not subsist, because the collusive behaviour oriented to a limitation of people's mobility cannot exist (except for environmental organisation that can buy permits in order to realise a baby sitting policy with the sole aim of reducing total private mobility).

The last element of complexity in the application of vehicle use permits is represented, even for passengers' mobility, by enforcement, control and sanctioning. For the system to work, the presence of monitoring mechanisms is needed in order to verify the attainment of the objectives of congestion reduction during peak-hours and to apply sanctions, high enough to act as a deterrent for possible illicit behaviours that could make the whole organisation of tradable permits system fruitless.

\section{Conclusions}

As it has been argued in the paper, the tradable permits policy has such characteristics that needs a large scale application, and will therefore cause a strong impact on urban mobility. When the opportunity of its application get envisaged, it is therefore necessary to take in high consideration the entity of its implementation cost, its political acceptance and the capacity to insert it in a multi-policy approach.

The application of the tool to freight transport seems less problematic than for passengers transport. With regard to political acceptance, this can be explained by the minor number of vehicles and by the possibility of direct bargaining with the trade associations. Besides, the integration with other policies represents a strength of applying tradable permits to freight transport. In fact, this policy seems to have particular synergy (possible improvement of carrying capacity and establishment of a physical market place) with the more and more common interchange platforms. Moreover, the coupling with the interchange platform will allow a considerable containment of operational costs (particularly transaction costs).

With regards to the application of the tool to passengers transport it is first of all necessary to notice that the entity of the transport, economic and political impact of such a tool is so strong to make it suitable only for highly critical 
context such as metropolis. In order to obtain a significant volume of permits exchange, it will certainly be necessary to support high costs, and therefore the advantage in terms of externalities reduction must be as much important. With regard to political acceptance, in order to make such a strong tool acceptable for population, it is again necessary that they face up a situation that is felt as hardly bearable. But even so, permits seem more easily acceptable than another tool, the road-pricing that is often advised for big cities. In the case of a free distribution of permits - beside the equity issue - while the road-pricing deters private mobility with the use of the stick, tradable permits encourage virtuous behaviour with the carrot, coupling the cost for using private vehicles (permit purchase) with a gain for using public transport (permit sale). At last, it must be noticed that, if we do not want to restrain the economical and social life of the city, the introduction of a tradable permits system cannot leave out of consideration a significant improvement in public transport. The increase of public transport sector revenues that will rise from the necessary transfer of part of the traffic from private to public transport could probably not be sufficient. For this reason, even if the free distribution of permits is possibly the strongest argument for tradable permits policy, the attractiveness of a yield for Public Authority and/or public transport is unfortunately an important argument against it.

\section{Acknowledgements}

The whole paper has been jointly discussed and developed by the authors. Nevertheless, $\S 1$ and 3 are by C.Burlando, $\S 2$ and 4 are by C.Sillig.

\section{References}

[1] Coase R. H., The problem of social cost. Journal of law and economics, 3, pp. $1-44,1960$

[2] Dales J. H., Pollution, property and price, University of Toronto Press: Toronto, 1968

[3] Camagni R., Economia e pianificazione della città sostenibile, il Mulino: Bologna, 1996

[4] Danielis R., I trasporti e l'ambiente, Giappichelli: Torino, 1996

[5] Pozzo B., La nuova direttiva sullo scambio di emisione, Giuffré: Milano, 2003

[6] CNT, Conseil National des Transports (Report), L'effet de serre et les transports: les potentialités des permis d'émissions négociables, July 2001, $\quad$ http://www.cnt.fr/NEWS/RAPPORTS/200107/24.L effet de serre et les Transports.shtml

[7] Goddard H. C., Using tradable permits to achieve sustainability in the world's large cities. Environmental and Resource Economics, 10, pp 63 99, 1997

[8] Raux C., The use of transferable permits in transport policy. Transportation Research Part D, 9, pp 185-197, 2004 
900 Urban Transport XII: Urban Transport and the Environment in the 21st Century

[9] Barret S.D., Barriers to contestability in the deregulated European aviation market, in Transportation Research, 26A (2), 1992

[10] Bonnafous A., Giret A. Complémentarité ou concurrence des aéroports: l'exemple du grand Sud-Est, in Géocarrefour, 77 (2), pp. 133-144, 2002

[11] Carlucci F., Trasporto aereo, regolamentazione e concorrenza, Cedam: Padova, 2003 